\title{
MONITORING OF CHEMICAL PARAMETERS OF QUALITATIVE PASTA SAMPLES CONTAINING MILLET FLOURS DURING STORAGE EXPERIMENTS
}

\author{
I. SzedluaK ${ }^{a *}$, K. SzÁntai-Köhegyi ${ }^{a}$, M. Tóth ${ }^{\mathrm{b}}$ and B. Bernhardt ${ }^{\mathrm{c}}$ \\ ${ }^{a}$ Department of Grain and Industrial Plant Technology, Faculty of Food Sciences, \\ Corvinus University of Budapest, H-1118 Budapest, Villányi út 29-43. Hungary \\ ${ }^{\mathrm{b}}$ Department of Food Engineering, Faculty of Food Sciences, Corvinus University of Budapest, \\ H-1118 Budapest, Ménesi út 45. Hungary \\ ${ }^{\mathrm{c}}$ Department of Medicinal and Aromatic Plants, Faculty of Horticultural Sciences, \\ Corvinus University of Budapest, H-1118 Budapest, Villányi út 29-43. Hungary
}

(Received: 8 April 2014; accepted: 22 July 2014)

\begin{abstract}
Millet has attracted a great deal of interest due to its valuable agricultural, nutritional, and functional properties. In this study the aim was the investigation of millet usability in dry pasta products. Chemical, enzymological, and sensory parameters were measured and monitored in Triticum aestivum, Triticum durum, and millet containing pasta products during a 12-month-long storage period. According to our results, during the storage, millet had a strong effect on different parameters: because of increased acid value, the shelf life was reduced, and millet significantly influenced the $\mathrm{pH}$ value and the water soluble polyphenol content. The highest scores were measured in T. durum and T. durum-millet pasta samples in the sensory test, while the T. aestivum-millet mixture pasta got the lowest scores. Also in our experiment we tested how the drying temperature modifies polyphenol oxidase enzyme (PPO) activity right after drying and during storage. The samples containing millet flour had higher PPO activity in all cases after drying, while pasta made with T. durum had the lowest PPO activity. Our results showed that drying temperature has a significant impact on PPO activity.
\end{abstract}

Keywords: millet, polyphenol, polyphenol oxidase, dry pasta

Millet (Panicum miliaceum L.) increasingly receives place in food processing nowadays, thanks to the promotion of nutrition's reform. Millet's short growing season and its versatile utility raise its value. Millet has a cholesterol lowering effect (HEDGE et al., 2005), which is proved by the results of several animal experiments. Millet has many benefits in diabetes therapy (RAJASEKARAN et al., 2004), as well as it plays an important role in health protection (TAYLOR et al., 2014). Millet contains very much silica, also contains fluorine, iron, magnesium, calcium, zinc, potassium and manganese (TAYLOR et al., 2014). It has got high carotenoid content, so the use of millet contributes to the excellent yellow colour of pasta (CHог et al., 2007). In addition it contains a high amount of vitamins (especially in B-group vitamins), and it reduces the GI (glycemic index) of the final products (CuBADDA et al., 2009; Shahidi \& ChANDRAsekara, 2013). Millet is gluten-free (TAYlor et al., 2014), so people suffering from coeliac disease can eat it, but clean millet, without any other cereal contamination, can only be produced with difficulty in our country. CHANDRASEKARA and SHAHIDI (2010) reported a wide range of phenolic compound concentrations and antioxidant capacities of millet. Phenolic compounds in millets are found in the soluble and insoluble-

\footnotetext{
* To whom correspondence should be addressed.

Phone: +36-1-482-6236; e-mail: ildiko.szedljak@uni-corvinus.hu
} 
bound forms (SHAHIDI \& CHANDRASEKARA, 2013). Free phenolic acids are found in the outer layers of the kernel (pericarp, testa, and aleurone), whereas the bound phenolic acids are associated with cell walls (Hahn et al., 1984; Heim et al., 2002; Dykes \& Rooney, 2006).

The pasta technology used in case of millet - which has very high nutritive value - is negligible in our country. Nevertheless several endemic diseases (diabetes, obesity, cancer, disorders of cardiovascular system) could be prevented with the continuous consumption of millet (CHANDRASEKARA \& SHAHIDI, 2011; Kim et al., 2011).

The main purpose of our work was to test and document the main quality parameters of pasta produced with and without millet $(\mathrm{pH}$, acid value, PPO activity, water-soluble polyphenol content) right after manufacturing and before expiration date.

\section{Materials and methods}

All kinds of flour (Triticum durum, Td; Triticum aestivum, Ta; Panicum miliaceum, Pm) used for processing pasta were purchased from the Hungarian market. Dry pastas were made of different flours and water. The codes of dry pastas and their flour compositions are shown in Table 1 .

Table 1. Dry pasta sample codes

\begin{tabular}{lc}
\hline Flour composition of pastas & Dry pasta sample codes \\
\hline $100 \%$ T. durum & $\mathrm{Td}$ \\
$100 \%$ T. aestivum & $\mathrm{Ta}$ \\
$70 \%$ T. durum - 30\% P. miliaceum & 70Td 30Pm \\
$60 \%$ T. durum - 40\% P. miliaceum & $60 \mathrm{Td} 40 \mathrm{Pm}$ \\
$50 \%$ T. durum - 50\% P. miliaceum & $50 \mathrm{Td} 50 \mathrm{Pm}$ \\
$70 \%$ T. aestivum - 30\% P. miliaceum & 70Ta 30Pm \\
$60 \%$ T. aestivum - 40\% P. miliaceum & $60 \mathrm{Ta} 40 \mathrm{Pm}$ \\
$50 \%$ T. aestivum - 50\% P. miliaceum & $50 \mathrm{Ta} 50 \mathrm{Pm}$ \\
\hline
\end{tabular}

Td: T. durum, Ta: T. aestivum, Pm: P. miliaceum

The pastas with different flour composition were made without any eggs. We could not produce pasta made of $100 \%$ P. miliaceum flour, because it is gluten-free and we did not want to add any food additives to dry pasta. Each pasta sample was manufactured in spindle shape. These pasta products were made by small-scale technology (extruder MAC 60-60 VR pasta machine, Italpast) and dried (maximum drying temperature $70{ }^{\circ} \mathrm{C}$ ). The length of storage process took 12 months, and the samples were taken on the first day of each month. Storage was carried out at $20-25{ }^{\circ} \mathrm{C}$ temperature and $75-85 \%$ relative humidity.

The moisture content was determined according to Hungarian standard MSZ (1985b) in a drying oven. The oven was thermostatically controlled by a heating chamber capable of maintaining a temperature of $110 \pm 5^{\circ} \mathrm{C}$.

The MSZ standard (1987) was used to determine the $\mathrm{pH}$ and acid values of the samples. 
Before extraction the samples were homogenized by a hammer mill grinder (KT 100) and the extracts were obtained $\left(0.10 \mathrm{~g} \mathrm{ml}^{-1}\right.$ in water after centrifugation for $10 \mathrm{~min}$ at $4{ }^{\circ} \mathrm{C}$ at 10000 r.p.m.). Chemicals were purchased from Sigma-Aldrich Co. and REANAL Finechemical Co.

Water soluble polyphenol content was measured by colorimetric method with Folin \& Ciocalteu's phenol reagent (Singleton \& Rossi, 1965) and the results were expressed in Gallic Acid Equivalent (GAE) value (mmol gallic acid per g dry weight of pasta).

The PPO activity was measured by using a synthetic substrate, pyrocatechol. The oxidized form of the substrate can be determined at $420 \mathrm{~nm}$ by spectrophotometer (WATSON \& FLURKEY, 1986).

All analyses were performed at least in five replicates. Standard deviation was within $\pm 5 \%$. Sensory properties of cooked pasta were evaluated by naive panellists (38 persons) using a 5-point category scale MSZ standard (1985a). External appearance (especially the colour of cooked pasta), taste, smell, and consistency of pasta samples were assessed.

\section{Results and discussion}

\subsection{Storage experiences}

$\mathrm{pH}$ values are shown in Figure 1A, 1B. Right after manufacturing, the $\mathrm{pH}$ value of pasta made of T. durum flour was 6.35 and that of T. aestivum flour was 6.28. By adding millet flour to the pasta, the $\mathrm{pH}$ values increased slightly - as tendencies - in both cases. During storage we observed that the $\mathrm{pH}$ values gradually decreased in all samples. At the end of storage, only in case of pastas made of T. aestivum and P. miliaceum flour mixture had the samples with millet flour higher $\mathrm{pH}$ values than the samples without millet flour.

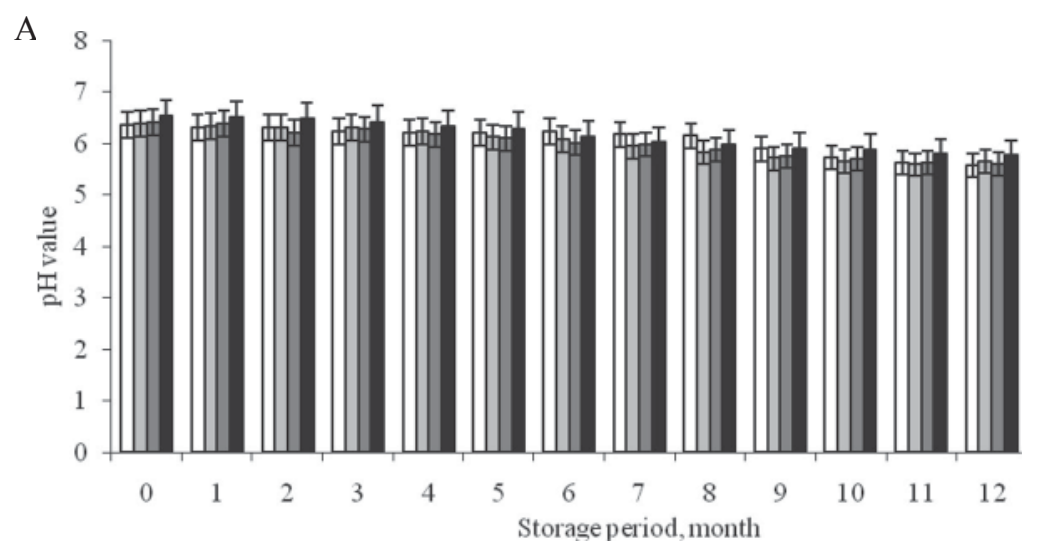

Fig. 1A. $\mathrm{pH}$ value of pastas made of T. durum and P. miliaceum flour mixture. $\square$ : Td; $\square: 70$ Td 30 Pm; $\square: 60$ Td 40 Pm; $\square: 50$ Td 50 Pm 


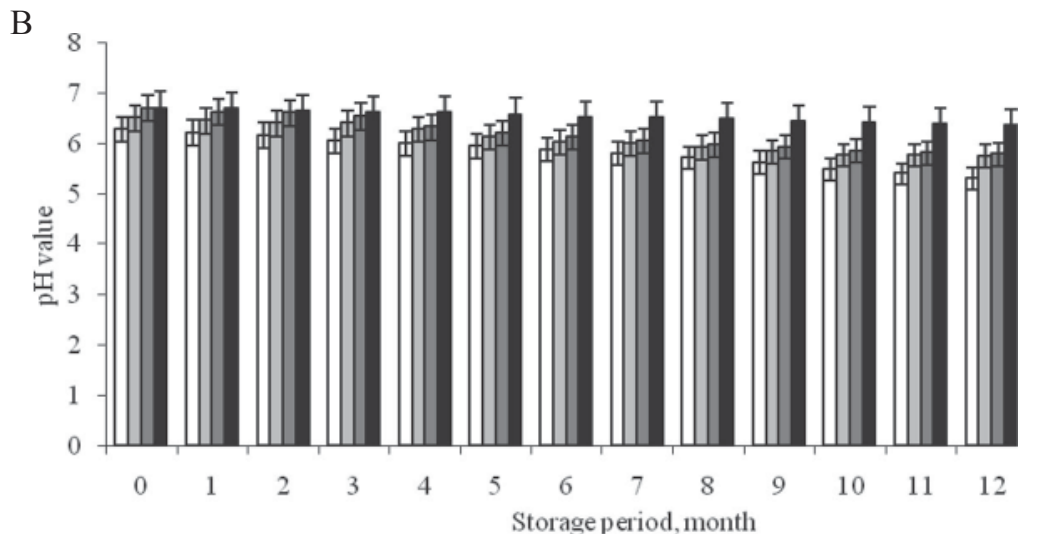

Fig. 1B. pH value of pastas made of T. aestivum and P. miliaceum flour mixture. $\square:$ Ta; $\square: 70$ Ta 30 Pm; $\square: 60$ Ta 40 Pm; $\square: 50$ Ta 50 Pm

The acid values can be seen in Figure 1C, 1D. Acid values of the pasta produced of T. durum and T. aestivum flour were the same (3.3) at the beginning of the storage period. The millet caused notable increase in the acid value. The more millet flour was added to the pasta dough the higher acid values were measured. The pasta samples containing 50\% T. aestivum and $50 \%$ millet flour had the highest acid value (4.9). Pastas with 5.0 or higher acid value would be rejected in the market because of not acceptable sensory properties. Based on these results, especially because of the increased acid value, it is necessary to reduce the shelf life of the samples containing millet compared with pastas which are made from traditional flours only.

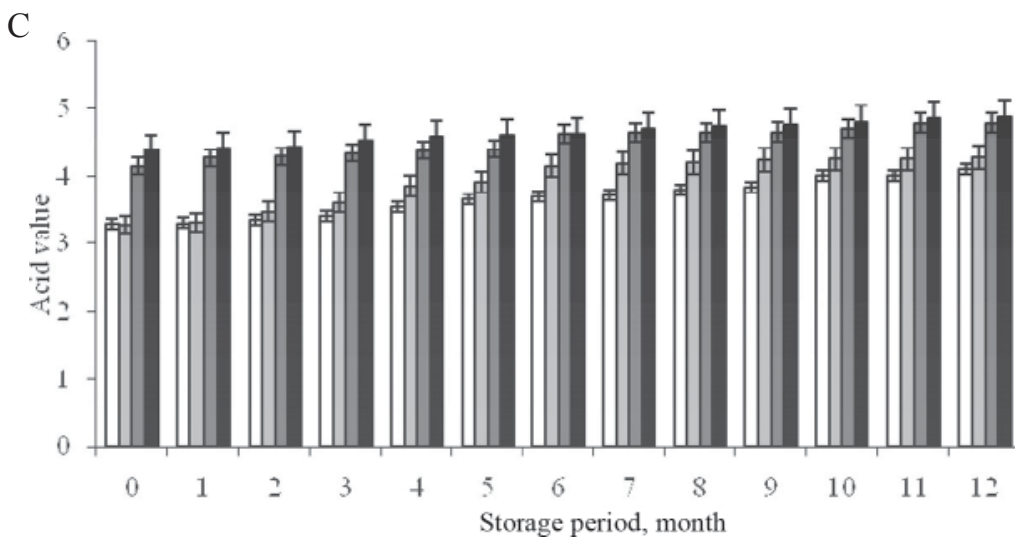

Fig. 1C. Acid value of pastas made of T. durum and P. miliaceum flour mixture. $\square:$ Td; $\square$ : 70 Td 30 Pm; $\square: 60$ Td 40 Pm; $\square: 50$ Td 50 Pm 


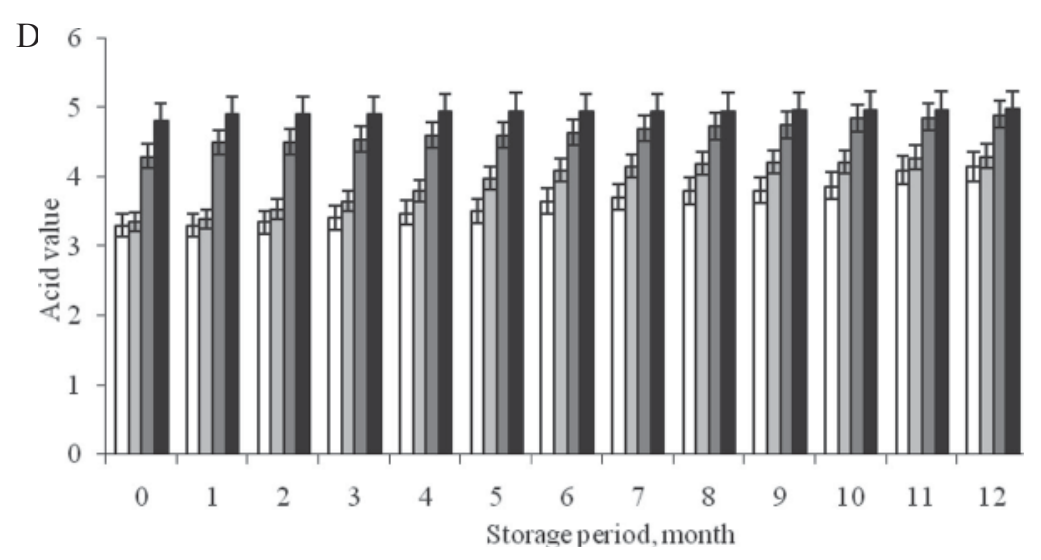

Fig. 1D. Acid value of pastas made of T. aestivum and P. miliaceum flour mixture. $\square:$ Ta; $\square: 70$ Ta 30 Pm; $\square: 60$ Ta 40 Pm; $\square: 50$ Ta 50 Pm

Figure 2A, 2B shows the water soluble polyphenol contents of pasta samples. Immediately after manufacturing, polyphenol content of pasta made of $T$. durum flour was three times higher than in pasta made of T. aestivum flour. In both samples the polyphenol content decreased significantly by the end of storage period. Usage of millet caused significant change in polyphenol content in dry pasta samples. The pasta samples containing $70 \%$ T. durum and $30 \%$ millet flour preserved the highest rate of polyphenol components during the 12-month storage ( $0.132 \mathrm{mmol}$ gallic acid per $\mathrm{g}$ dry weight of pasta, GAE $\mathrm{g}^{-1}$ value).

A gradual reduction of the soluble polyphenol content was observed during storage, but the millet flour contributed to the nutritional value of pastas in all cases. At the end of the storage period, the polyphenol content of pasta samples containing $60 \%$ T. aestivum and $40 \%$ millet flour was ten times higher than that of $100 \%$ T. aestivum flour pasta.

By adding millet flour to the pasta dough, the amount of phenolic compounds increased significantly in the dry pasta products.

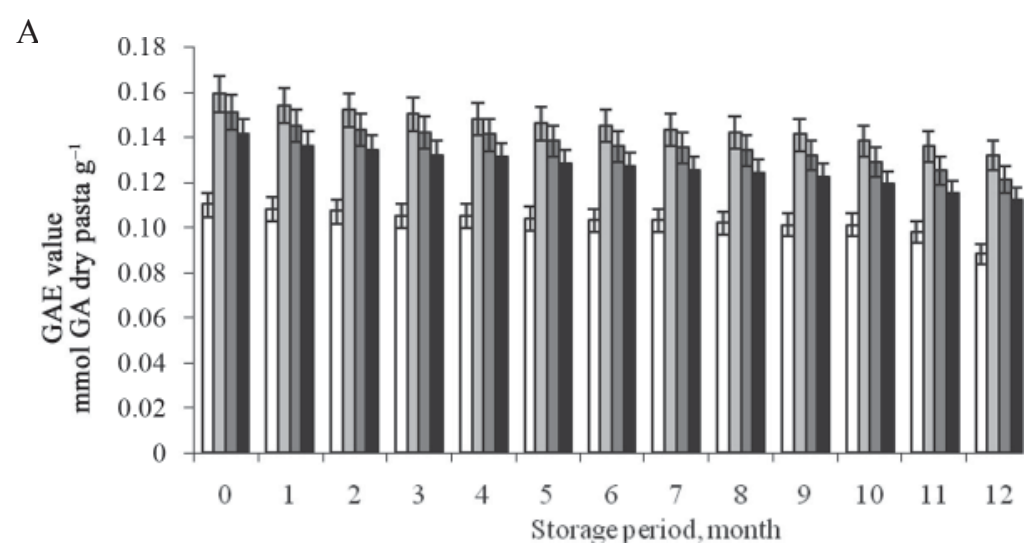

Fig. 2A. Water soluble polyphenol content of pastas made of T. durum and P. miliaceum flour mixture. $\square:$ Td; $\square: 70$ Td 30 Pm; $\square: 60$ Td 40 Pm; $\square: 50$ Td 50 Pm 
B

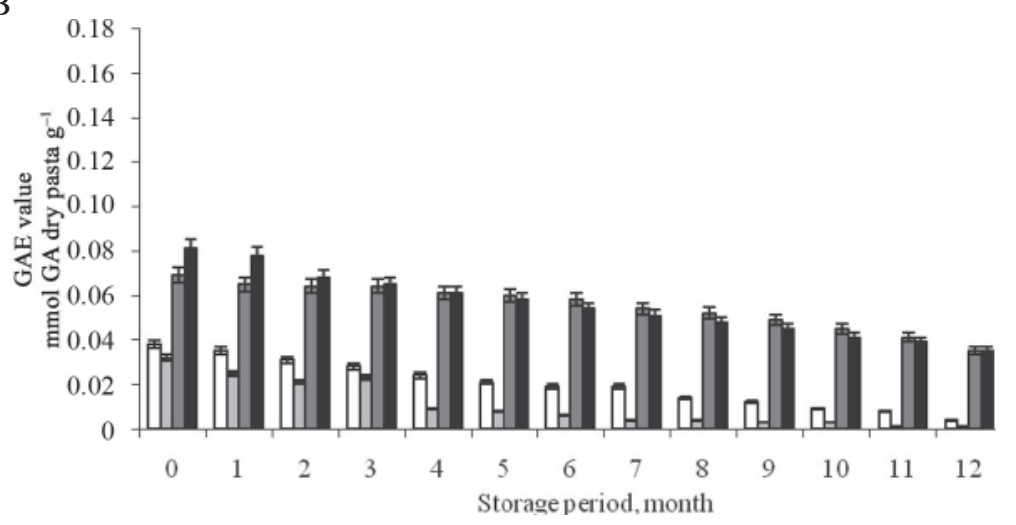

Fig. 2B. Water soluble polyphenol content of pastas made of $T$. aestivum and P. miliaceum flour mixture. $\square:$ Ta; $\square: 70$ Ta 30 Pm; $\square: 60$ Ta 40 Pm; $\square: 50$ Ta 50 Pm

\subsection{Sensory assessment}

All pasta products were evaluated according to the MSZ (1985). The external appearance of pasta samples was judged by 38 panellists at the beginning and the end of storage. The panellists gave maximum value (20 points) for pasta samples containing 30\% millet and $70 \%$ T. durum flour. The pastas with 100\% T. durum flour also got 20 points after manufacturing, at the end of storage their score was 18 . Pastas with $50 \%$ and $60 \%$ millet flour were classified into quality class 2 with $15-14$ points. A decrease in quality was observed in all cases in the $12^{\text {th }}$ month. None of the samples got maximum score at the end of storage. Pasta samples containing 50\% T. aestivum and 50\% millet flour were judged as not acceptable pastas as they had unpleasant odour, their cooking quality decreased, and the dry pastas were fragile.

\subsection{PPO activity}

The properties of pastas are also determined by their PPO activity, which is influenced by their total phenol content. During our experiments we tested how the drying temperature modifies PPO activity right after drying and during storage. Drying was carried out at 50, 60, and $70{ }^{\circ} \mathrm{C}$ temperature. PPO activity could only be measured in four pasta samples $(100 \% \mathrm{Td}$, $100 \% \mathrm{Ta}, 70 \% \mathrm{Td} 30 \% \mathrm{Pm}$, and 70\% Ta 30\% Pm) after drying. In other samples there was no detectable PPO activity. Results can be seen in Fig. 3. The lowest PPO activity was measured in the samples made of $100 \%$ T. durum flour. Raising the temperature from $50{ }^{\circ} \mathrm{C}$ to $70{ }^{\circ} \mathrm{C}$, the PPO activity in the samples made of $100 \%$ T. durum flour decreased from 125 to $82 \mathrm{U}$ per g dry pasta. The samples containing millet flour had higher PPO activity in all cases after drying. Raising the temperature from $50{ }^{\circ} \mathrm{C}$ to $60{ }^{\circ} \mathrm{C}$, the PPO activity in the samples made of $70 \%$ T. aestivum and $30 \%$ millet flour decreased at a negligible degree. The drying at $70{ }^{\circ} \mathrm{C}$ resulted in significant decrease in PPO activity. PPO activity values were checked during the whole storage period but we could not detect any PPO activity after onemonth storage. According to our results we can declare that the increasing drying temperature definitely decreased the PPO activity, however, by adding millet flour to the pasta dough increased it significantly (Fig. 3). The drying temperature did not have any effect on PPO activity during storage (data not shown). 


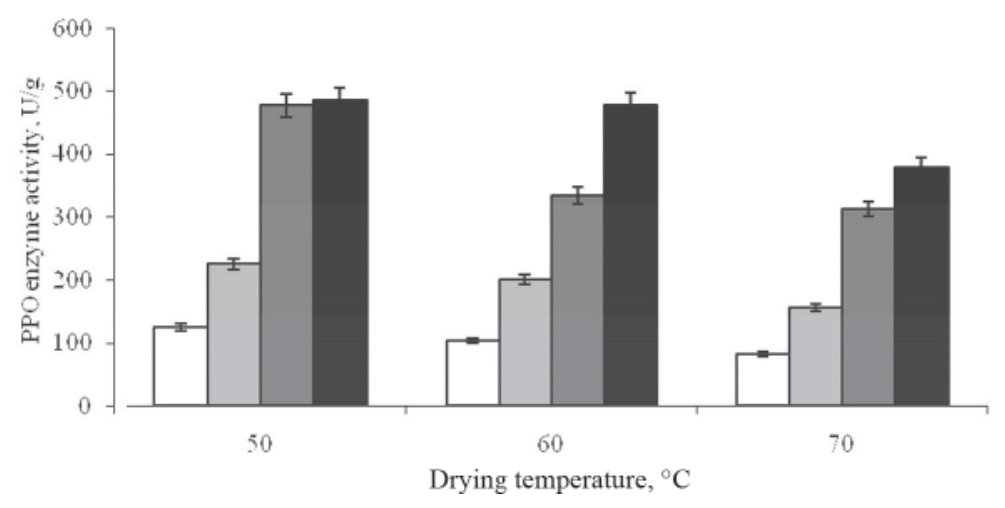

Fig. 3. PPO enzyme activity after drying.

$\square:$ Td; $\square: 70$ Td 30 Pm; $\square: 60$ Td 40 Pm; $\square: 50$ Td 50 Pm

We did not find any relevant literature sources to the comparison of the above-mentioned parameters determined by us for our pasta products. An important objective of our work was to fill this gap.

\section{Conclusions}

The use of millet flour - because of its outstanding nutritional properties - became increasingly important in our country in the pasta processing. Beyond the improvement of the nutritional value, the millet flour - which has high yellow pigment content - allows to make pleasant colours and appropriate quality of pasta products without using eggs. This is confirmed by the results of our sensory tests.

Using different proportions of millet flour in pasta production clearly affects the determining quality parameters $(\mathrm{pH}$, acidity values, water-soluble polyphenol content, PPO activity, organoleptic characteristics) of the fresh and stored (12 months) pasta samples. Based on the measured characteristics, the highest quality product contained $30 \%$ millet and $70 \%$ T. durum flour. It was concluded that the use of millet allows making finished products with higher polyphenol content. Too high (50\% or higher) proportion of millet in dough's flour mixture resulted significant rise in acidity during storage, which is not a favourable phenomenon.

Acknowledgements: The authors are grateful to TÁMOP 4.2.1./B09/01/KMR/2010-0005 and Füri Pasta and Food Marketing Ltd. (GOP-1.1.1-09/01) for the financial support.

\section{References}

Chandrasekara, A. \& Shahidi, F. (2010): Content of insoluble bound phenolics in millets and their contribution to antioxidant capacity. J. Agric. Food Chem., 58, 6706-6714.

Chandrasekara, A. \& Shahidi, F. (2011): Antiproliferative potential and DNA scission inhibitory activity of phenolics from whole millet grains. J. Funct. Foods, 3(3), 159-170. 
Chol, Y., Jeong, H.-S. \& LeE, J. (2007): Antioxidant activity of methanolic extracts from some grains consumed in Korea. Food Chem., 103, 130-138.

Cubadda, F., Aureli, F., RagGi, A. \& Carcea, M. (2009): Effect of milling, pasta making and cooking on minerals in durum wheat. J. Cereal Sci., 49(1), 92-97.

Dykes, L. \& Rooney, L.W. (2006): Review. Sorghum and millet phenols and antioxidants. J. Cereal Sci., 44(3), 236-251.

Hahn, D.H., Rooney, L.W. \& EARP, C.F. (1984): Tannins and phenols of sorghum. Cereal Foods World, 29, 776779.

Hedge, P.S., Rajasekaran, N.M. \& Chandra, T.S. (2005): Effects of the antioxidant properties of millet species on oxidative stress and glycemic status in alloxan-induced rats. Nutr. Res., 25, 1109-1120.

Heim, K.E., Anthony, R.T. \& Dennis, J.B. (2002): Flavonoid antioxidants: chemistry, metabolism and structureactivity relationships. J. Nutr. Biochem., 13(10), 572-584.

Kiм, J.-S., Hyun, T.K. \& Кім, M.J. (2011): The inhibitory effects of ethanol extracts from sorghum, foxtail millet and proso millet on $\alpha$-glucosidase and $\alpha$-amylase activities. Food Chem., 124, 1647-1651.

MSZ (1985a): Száraztészták vizsgálati módszerei. Fizikai vizsgálatok. (Test methods of pastry products. Testing physical properties.) MSZ 20500-1:1985

MSZ (1985b):Száraztészták vizsgálati módszerei. Kémiai vizsgálatok. (Pastry products. Test methods. Chemical analysis.) MSZ 20500-2:1985

MSZ (1987): Lisztvizsgálati módszerek. A pH, a savfok és a zsírsavszám meghatározása. (Flour test methods. Determination of $\mathrm{pH}$ acidity degree and fat acidity.) MSZ 6369-11:1987

Rajasekaran, N.S., Nithya, M., Rose, C. \& ChandRa, T.S. (2004): The effect of finger millet feeding on the early responses during the process of wound healing in diabetic rats. Biochim. Biophys. Acta, 1689(3), 190-201.

Shahidi, F. \& ChandRasekara, A. (2013): Millet grain phenolics and their role in disease risk reduction and health promotion: A review, J. Funct. Foods, 5(2), 570-581.

Singleton, V.L. \& Rossi, J.A. (1965): Colorimetry of total phenols with phosphomolybdic-phosphotunstic acid reagents. Am. J. Enol. Vitic., 16(3), 144-158.

Taylor, J.R.N., Belton, P.S., Beta, T. \& Duodu, K.G. (2014): Increasing the utilisation of sorghum, millets and pseudocereals: Developments in the science of their phenolic phytochemicals, biofortification and protein functionality. J. Cereal Sci., 59, 257-275.

WATSON, R.A. \& FLURKEY, W.H. (1986): Use of contact prints for recording polyphenoloxidase isoenzymes separated by electrophoresis, J. Sci. Food Agric., 37, 791-796. 